\title{
Curious Case of Spontaneous Colocutaneous Fistula
}

Sameer $D^{1 *}$, Neil $\mathbf{S}^{1}$, Prathamesh $\mathbf{P}^{1}$ and M. Amir ${ }^{1}$

${ }^{1}$ MBBS, General surgery resident at Bombay Hospital, an Assistant Professor, Maharashtra University of health sciences, Nashik p Postgraduate Teacher, Bombay hospital Institute of Medical Sciences

*Corresponding Author: Sameer D, MBBS, General surgery resident at Bombay Hospital, India.

Received date: August 18, 2021: Accepted date: September 16 2021: Published date: October 06,2021

Citation: Sameer D, Neil S, Prathamesh P, M. Amir (2021) Curious Case of Spontaneous Colocutaneous Fistula

J. Sur cas rep and stu 4(7); DOI: 10.31579/2690-1897/092

Copyright: (C) 2021 Sameer D. This is an open access article distributed under the Creative Commons Attribution License, which permits unrestricted use, distribution, and reproduction in any medium, provided the original work is properly cited

\begin{abstract}
A colocutaneous fistula is an infrequent condition, which often occurs as a post- surgical complication, while a spontaneous colocutaneous fistula is an even rarer occurence, which may be seen in conditions like diverticulitis or Crohn's disease. Cases of colocutaneous fistulas as a sequelae of endometriosis are very rare. Here, we present a case report of a 38 year old lady who presented developed a spontaneous colo-cutaneous fistula secondary to endometriosis involving the sigmoid colon.

Keywords: colocutaneous fistula; colon; Crohn's disease
\end{abstract}

\section{Presentation of Case}

A 38 year old lady, had presented with complaints of sudden onset pain and swelling in the left hip region since 3 days and fever since 3 days. The patient was a known case of hypothyroidism and endometriosis. The patient had previously been operated upon for the endometriosis in 2017, when an abdominal hysterectomy with bilateral salpingo- oophorectomy was performed. Histopathological examination, revealed the presence of a chocolate cyst of endometriotic tissue in the left ovary. However, subsequent radiological examinations after the surgery had revealed the presence of persistence of small amount of endometriotic tissue in the left iliac region, for which the patient had been receiving symptomatic treatment. At the time of examination, the patient was hemodynamically stable and febrile, with a temperature of $100.6 \mathrm{deg}$ F (38.1 deg C). Local examination revealed the presence of a swelling in the left gluteal region of size $5 \times 4 \mathrm{~cm}$. The skin overlying the swelling was red in colour and tender to touch, but there was no obvious discharge from the region. Abdominal examination was otherwise normal. Cardiovascular, Respiratory and Neurological examination was normal. Provisional diagnosis of an intra- gluteal abscess was made. She was started on intravenous antibiotics, fluids and analgesics. Her blood work showed the presence of a low hemoglobin level of 6.2 and a white cell count of 31,000 . An ultrasonography of the left gluteal region revealed the presence of an evolving abscess with solid tissue and no liquid components. A 2 month old MRI Abdomen of the patient revealed the presence of complex inhomogenously enhancing diffused soft tissue in the left lumbar, iliac and pelvic regions, which was inseparable from the iliopsoas muscle and was eccentrically involving the sigmoid colon and rectosigmoid junction. MRI Abdomen of the patient showing the endometriotic tissue involving the sigmoid colon and iliopsoas muscle. 


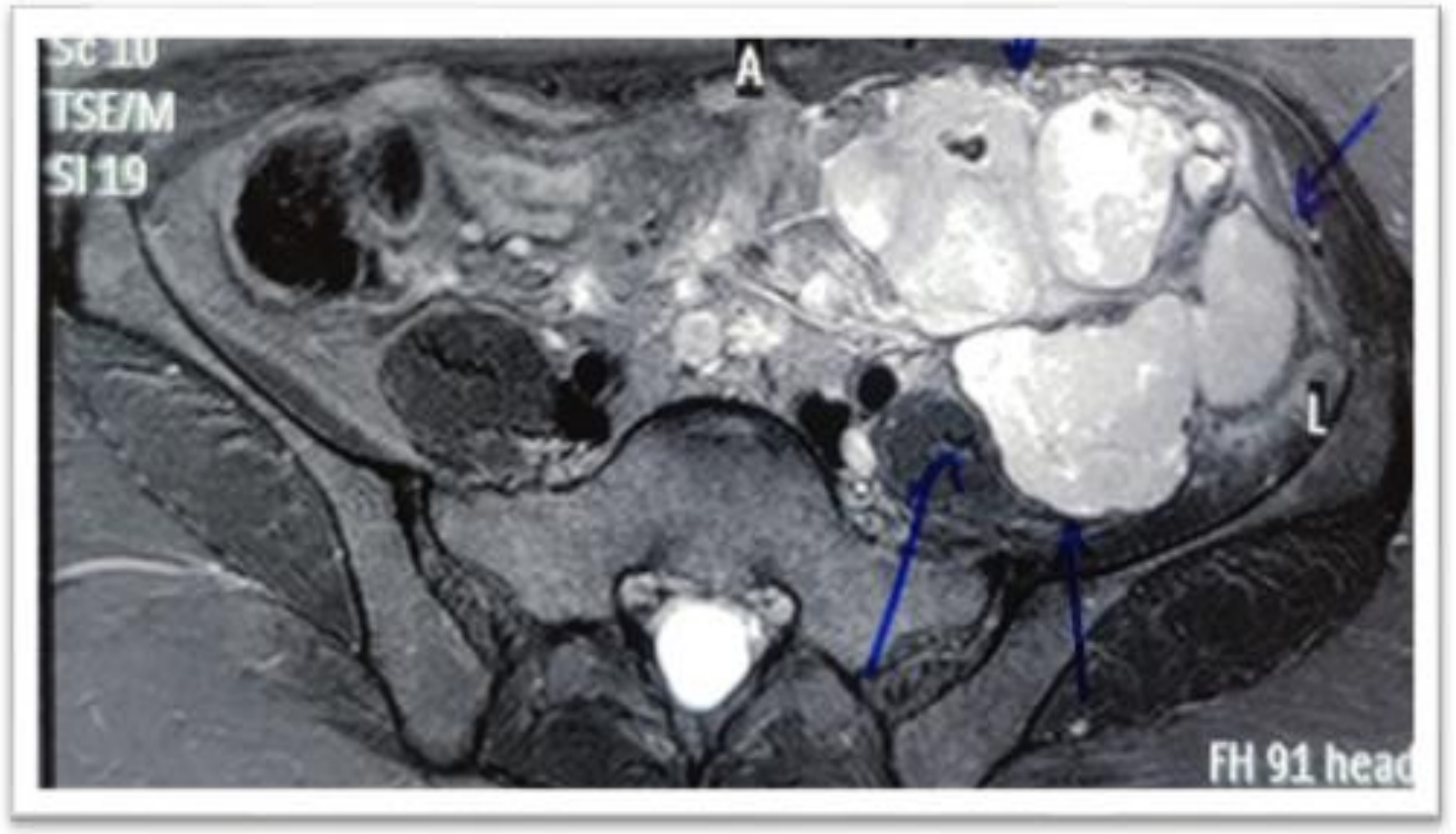

\section{Figure 1}

Within a few hours after admission, the condition of the patient deteriorated. The patient became drowsy and disoriented, was hypotensive, tachycardic and tachypneic. She was shifted to the ICU, where she was started on vasopresssor infusion and relative hemodynamic stability was achieved. In the meantime, the skin overlying the swelling became necrotic and there was the presence of subcutaneous emphysema in the skin surrounding the swelling. The patient was taken into the OT for debridement of the necrotic tissue, after optimization of general condition. During the debridement process, large amount of liquid fecal matter started coming from within the depth of the abscess cavity. Onspot decision to do an emergency laparotomy was done. Intra- abdominal findings showed the descending colon and sigmoid colon to be completely plastered onto the lateral abdominal wall. A transverse colostomy was fashioned and a thorough intra- abdominal wash was given. The patient was shifted to the ICU for further management.Spontaneous colocutaneous fistula which had liquid faeces dribbling out of it

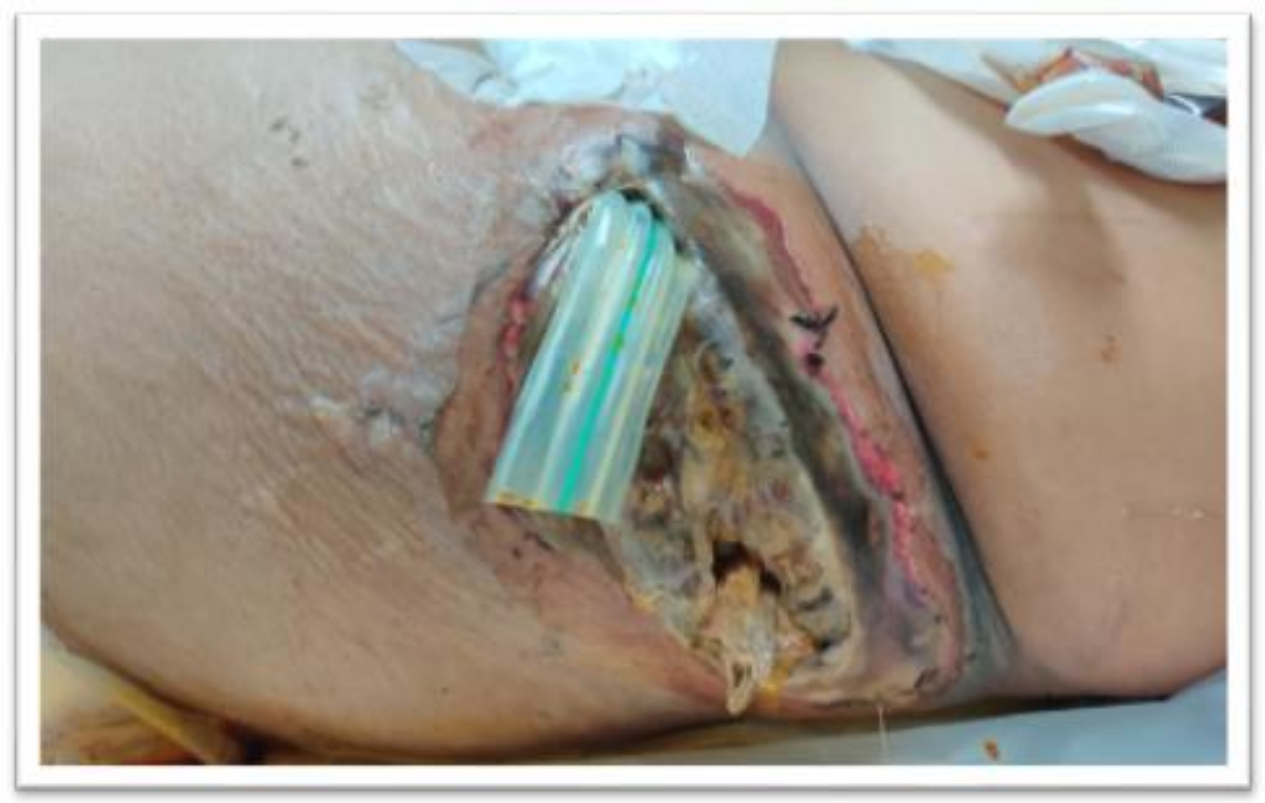

\section{Figure 2}

For first 48 hours, patient showed signs of improvement like urine output and blood pressure maintained without vasopressor support, breathing improved on ventilator and early extubation was planned. However, from latter part of post- op day 3 , her general condition started deteriorating and before a second debridement of the abscess cavity was to be carried out on post- op day 4 , she had a cardiac arrest and died. This case merits a post- mortem study to find out the cause of death, but this could not be done due to the patient's relatives refusal to give consent. 


\section{Summary}

Endometriosis refers to the proliferation and function of endometrial tissue at an extrauterine site, usually the pelvic peritoneum or reproductive organs. Many theories have been proposed to explain the pathogenesis of endometriosis. The most often cited theory that of implantation, proposes that the physiological phenomenon of endometrial reflux in the fallopian tubes during menstruation may, in certain conditions, overcome local defense mechanisms, implant, and proliferate at various sites [2]. Another theory about endometriosis, known as the metaplasia theory, suggests that under various influences, coelomic tissue can be converted into endometriotic tissue. The popular Sampson hypothesis of retrograde menstruation tries to explain how endometriosis has been reported in more distant locations, such as lungs, pleura and the umbilicus [2]. Intestinal endometriosis occurs in $12 \%$ to $15 \%$ of cases, most often affecting those segments located within the pelvis, such as the terminal ileum, the appendix, the sigmoid colon and the rectum, both above and below the peritoneal reflection. The most common sites are the rectosigmoid [up to $73 \%$ of cases] and rectovaginal septum [13\%]. It predominantly involves the extra mucosal layers [3]. Despite extensive serosal and intramural involvement, the intestinal mucosa usually remains intact and the endometrial perforation of the affected bowel is a very rare complication, which generally occurs in pregnant females. Endometriosis involving the intestine usually takes the form of asymptomatic, small, superficial serosal implants on segments of bowel lying in the pelvis in proximity to the genital organs. Deeper and more extensive intestinal wall involvement may result in obstruction and occasionally bleeding and requires distinction from a neoplasm or other inflammatory bowel process. Intestinal endometriosis should be considered in the differential diagnosis of recurring lower abdominal pain and other episodic bowel symptoms in women of child-bearing age. The diagnosis may be suspected based on the patient's history and frequently associated gynecologic symptoms [4]. We believe that this particular combination of endometriosis leading to colonic perforation followed by the formation of a spontaneous colocutaneous fistula is extremely unusual. The treatment of uncomplicated intestinal endometriosis depends on the patient's age and intention to conceive. Bowel resection is indicated if there are symptoms of obstruction or bleeding, and if malignancy cannot be excluded. In patients of child-bearing age, resection of the involved colon followed by hormonal treatment may be sufficient; otherwise, hysterectomy and bilateral oophorectomy is the treatment of choice [5].

\section{References}

1. Fagan: Endometriosis-clinical and roentgenographic... - Google Scholar [Internet]. [cited 2021 Aug 5]. Available from:

2. Garg NK, Bagul NB, Doughan S, Rowe PH. Intestinal endometriosis-A rare cause of colonic perforation. World $\mathrm{J}$ Gastroenterol WJG. 2009 Feb 7;15(5):612-4.

3. D'Hooghe TM, Debrock S. Endometriosis, retrograde menstruation and peritoneal inflammation in women and in baboons. Hum Reprod Update. 2002 Feb;8(1):84-8.

4. Croom RD, Donovan ML, Schwesinger WH. Intestinal endometriosis. Am J Surg. 1984 Nov;148(5):660-7.

5. Vinatier D, Orazi G, Cosson M, Dufour P. Theories of endometriosis. Eur J Obstet Gynecol Reprod Biol. 2001 May;96(1):21-34.

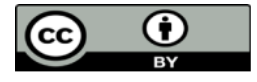

This work is licensed under Creative Commons Attribution 4.0 License

To Submit Your Article Click Here: Submit Manuscript

DOI: $10.31579 / 2690-1897 / 092$

\author{
Ready to submit your research? Choose Auctores and benefit from: \\ $>$ fast, convenient online submission \\ $>$ rigorous peer review by experienced research in your field \\ $>$ rapid publication on acceptance \\ $>$ authors retain copyrights \\ $>$ unique DOI for all articles \\ $>$ immediate, unrestricted online access
}

At Auctores, research is always in progress.

Learn more https://auctoresonline.org/journals/journal-of-surgical-casereports-and-images 